\title{
Roots \& Shoots: A model for active environmental protection
}

Patrick O. Waeber

\section{SUMMARY}

Madagascar is facing severe environmental problems. One approach to engage possible future stakeholders and to raise awareness for environmental concerns is the Roots \& Shoots program. On the following the program and its philosophy are presented.

MADAGASCAR - THE DEMOGRAPHIC SITUATION Madagascar has a current population of about 18 million people living across the more than $587,000 \mathrm{~km}^{2}$ big islands. Madagascar is among the top ten countries in the world concerning birth rate ( $>3 \%$, world average: $1.15 \%$ ). More than 8 million Malagasy are under 15 years old. Thus, a bit less than $50 \%$ of the whole population are children.

In the meantime, the environment on this island is facing fast changes it cannot cope with. Those comprise soil erosion resulting from deforestation and overgrazing through cattle, desertification, contamination of surface water with raw sewage and other organic wastes. Hence, the living conditions for a majority of the Malagasy population is changing to the worse and surviving has become a daily challenge.

The future for millions of people is not at all bright. Always the weakest in a community are the first to suffer negative impacts of environmental changes: children and old people.

\section{THE ROOTS \& SHOOTS PROGRAM}

Roots \& Shoots (R\&S) program engages children and young people through community service and service learning. The children are organized in groups of 2 up to 40 or more children with for example a teacher or an adult person taking over the lead and responsibility for the group. Roots \& Shoots groups show care and concern in three different areas: the human community (social environment), the animals (wild and domestic) and the natural environment. The main goal of R\&S is to raise the children's awareness as well as the public's one for these areas by doing small projects with their groups. The importance thereby is that the children get the possibility to plan and implement their actions by their own. The group leaders are there to coordinate and support the children's activities.

THREE KEYNOTES ARE THE CORE OF R\&S: Knowledge: The more children know about their community or environment, the better they can judge what needs to be done. The more children know and understand the higher is the chance to
Jane Goodall Institute Switzerland

Germaniastrasse 51

$\mathrm{CH}-8006$ Zurich

Switzerland

E-mail: pawaeber@janegoodall.ch develop Compassion: The concern and a desire to make a difference energize young people to tackle problems around them. This has as a logical consequence the third keynote - Action: Action is the result of a group's learning and planning. These three steps are crucial for a success and serves as starting point for the R\&S program. Furthermore, the knowledge-compassion-action-pathway is to be achieved in all the mentioned areas of R\&S activity.

Roots \& Shoots has been founded in 1991 by Dr. Jane Goodall in Tanzania and embraces today 96 countries with more than 100,000 children worldwide. An R\&S group can work by its own or use the network and have a steady exchange of ideas and actions with a group from another region or even another country. This gives the children the possibility to learn and know more about other regions and cultures. Furthermore, this is an important reason to enhance children's motivation to participate in such a program.

\section{ROOTS \& SHOOTS MADAGASCAR}

In October 2005 Roots \& Shoots Madagascar has been founded with Todinaina Ralasondraibe as the Coordinator of R\&S Madagascar. Until now he has founded 6 groups: one at the Malagasy East Coast, two in Antananarivo and three in the Alaotra Region. The best way to engage as many children as possible is to involve primary and secondary schools into the R\&S program. The goals of Roots \& Shoots Madagascar are to build a network of groups in each of the 6 provinces of Madagascar to cover all the 5 geographic regions with the respective and diverse habitats. The long-term goal in Madagascar is to engage the students at the university level, because they are the most closely future stakeholders.

On the following, an example of action is presented: The group 'Domoina' (composed of children from the $3^{\text {rd }}-5^{\text {th }}$ secondary school level) learns about lemurs as a Malagasy heritage and peculiarity. They make draws of the lemurs, which they have visited and seen in the Tsimbazaza Zoo in Antananarivo. These draws are exposed in their school. Further, the R\&S members will present in their respective classes what they have learned about lemurs: the importance of the lemurs, the threats which most of the lemurs faces, and possible solutions to preserve the lemurs for the future. 


\section{ROOTS \& SHOOTS - AN ACTION-PLAN FOR THE}

\section{LONG-TERM SCALE}

Together, the Roots \& Shoots philosophy can be a way to engage as many children and young people as possible across the whole islands of Madagascar taking action for their environment and their future. Only if children of today learn about the importance of their environment, the men and women of tomorrow can handle it with care. Therefore, Roots \& Shoots is not only a way to take action for the short-term, but it is an action-plan with sustainable potential on a long-term scale.

\section{ACKNOWLEDGMENTS}

First of all I would like to give the Misaotra Betsaka to the Roots \& Shoots Coordinator Madagascar, Todinaina Ralasondraibe, for his great effort in Madagascar and for his continuous feedbacks on the R\&S activities in Madagascar. I would like to thank Nona Gandelman and Mary Lewis from the Jane Goodall Institute for their helpful comments and reading of the article.

\section{REFERENCES}

The World Factbook: http://www.cia.gov/cia/publications/factbook/geos/

$$
\text { ma.htm }
$$

The Jane Goodall Institute, Roots \& Shoots: http://www.rootsandshoots.org/ 